\title{
Enhancement in Mode II Interlaminar Fracture Toughness at Cryogenic Temperature of Glass Fiber/Epoxy Composites through Matrix Modification by Carbon Nanotubes and n-Butyl Glycidyl Ether
}

\author{
Yu Liu, Cheng-Bing Qu, Qing-Ping Feng, Hong-Mei Xiao, and Shao-Yun Fu \\ Technical Institute of Physics and Chemistry, Chinese Academy of Sciences, Beijing 100190, China \\ Correspondence should be addressed to Hong-Mei Xiao; hmxiao@mail.ipc.ac.cn and Shao-Yun Fu; syfu@mail.ipc.ac.cn
}

Received 12 June 2014; Accepted 27 August 2014

Academic Editor: Cheng Yan

Copyright (C) 2015 Yu Liu et al. This is an open access article distributed under the Creative Commons Attribution License, which permits unrestricted use, distribution, and reproduction in any medium, provided the original work is properly cited.

A typical diglycidyl ether of bisphenol-F (DGEBF)/diethyl toluene diamine (DETD) epoxy system modified by multiwalled carbon nanotubes (MWCNTs) and a reactive aliphatic diluent named n-butyl glycidyl ether (BGE) was used as the matrix for glass fiber composites. The glass fiber (GF) reinforced composites based on the unmodified and modified epoxy matrices were prepared by the hand lay-up hot-press process. Mode II interlaminar fracture toughness at both room temperature (RT) and cryogenic temperature $(77 \mathrm{~K})$ of the GF reinforced epoxy composites was investigated to examine the effect of the matrix modification. The result showed that the introduction of MWCNTs and BGE at their previously reported optimal contents led to the remarkable enhancement in mode II interlaminar fracture toughness of the composites. Namely, the $22.9 \%$ enhancement at RT and the $31.4 \%$ enhancement at $77 \mathrm{~K}$ were observed for mode II interlaminar fracture toughness of the fiber composite based on the optimally modified epoxy matrix by MWCNTs and BGE compared to the unmodified case.

\section{Introduction}

It is well known that matrices play a very important role in load transfer and crack resistance and hence significantly affect the mechanical properties of fiber reinforced composites. Epoxy resins are most popular matrices for fiber reinforced composites. Due to their shortages such as high brittleness, they are often modified by toughening agents. In our previous work [1], a reactive aliphatic diluent, namely, n-butyl glycidyl ether (BGE), was displayed to be a proper toughening agent for modifying epoxy resins. On the other hand, carbon nanotubes (CNTs) have exhibited excellent mechanical properties and also demonstrated a great potential as toughening agents for modifying epoxy resins [2-6].

Delamination of the composite laminates would take place when shear and peeling stress concentrations were high. And the fracture toughness under shear loading (i.e., mode
II interlaminar fracture toughness) is a critical property to evaluate the potential crack growth resistance [7]. Therefore, mode II interlaminar fracture toughness $\left(G_{\text {IIc }}\right)$ is an important parameter for design of composites in practical applications. Shindo et al. [7] investigated $G_{\text {IIc }}$ of glass fiber reinforced epoxy composites at cryogenic temperature. However, there is no report yet about mode II interlaminar fracture of fiber reinforced composites based on modified epoxy resins especially by both stiff modifier like CNTs and soft modifier such as BGE.

In our previous work [8], it has been demonstrated that the $0.5 \mathrm{wt} \%$ content of multiwalled CNTs was the optimal amount for modifying the epoxy resins since a higher CNT content would lead to CNT aggregates and thus deteriorated the epoxy performance. On the other hand, reactive BGE has also been displayed to have an effective role in modifying epoxy resins at the optimal content of $10 \mathrm{wt} \%$ [8]. At these optimal contents, the glass fiber reinforced composites based 
on modified epoxy resins have shown great enhancements in tensile properties [9] and interlaminar shear strength at RT [10].

In this work, the diglycidyl ether of bisphenol $\mathrm{F}$ (DGEBF)/diethyl toluene diamine (DETD) epoxy system modified by multiwalled CNTs and BGE was prepared according to our previous works $[1,8-10]$ as the matrix. The glass fiber reinforced composites based on the unmodified and modified matrices were fabricated by the hand lay-up hot press process. Mode II interlaminar fracture toughness $\left(G_{\text {IIc }}\right)$ at RT and $77 \mathrm{~K}$ of the glass fiber reinforced composites based on the unmodified and modified epoxy resins was investigated to examine the effect of matrix modification by multiwalled carbon nanotubes (MWCNTs) and BGE. The significant enhancement in mode II interlaminar fracture toughness at both RT and $77 \mathrm{~K}$ of the glass fiber reinforced composite was observed by the modification of the epoxy at the optimal contents of MWCNTs and BGE.

\section{Experimental}

2.1. Materials. Woven E-glass fibers (GF) were purchased from Feihangtongda Co., Ltd., China. The average diameter of single GF was about $11 \mu \mathrm{m}$. The epoxy resin used in this work was diglycidyl ether of bisphenol-F (DGEBF, D.E.R.354, Dow Chemical Co., USA) with the epoxide weight equivalence in the range of 167-174. The curing agent was diethyl toluene diamine (DETD, Kunshan Chemical Material Co., Ltd., China), which is a mixture of the two DETD isomers (74-80 wt.\% 2,4-isomer and 18-24 wt.\% 2,6-isomer). n-Butyl glycidyl ether (BGE, Changshu Jiafa Chemistry Co., Ltd., China) was used as a soft modifier for epoxy resin. Multiwalled carbon nanotubes (MWCNTs) made by CVD (purity >95wt.\%, Chengdu Organic Chemicals Co., Ltd., China) were employed as a stiff modifier for epoxy resins. The diameters of the nanotubes were in the range of $30-50 \mathrm{~nm}$ and the length was between 10 and $20 \mu \mathrm{m}$ [8]. The chemical structures of DGEBF, DETD, and BGE have been given in our previous work [9].

2.2. Preparation of Composites. The preparation of the glass fiber reinforced epoxy composite has been given in detail in our previous works [10] and is briefly described here. First, the modified epoxy matrix was prepared by mixing epoxy resins and other additives at $50^{\circ} \mathrm{C}$. The pure epoxy system was also employed as the matrix for the purpose of comparison. Formulations of unmodified and modified epoxy resins as matrices are shown in Table 1. Second, glass fiber clothes were impregnated with these epoxy resins. Twenty impregnated prepregs were stacked via the hand layup method and glass fiber reinforced composites based on the unmodified and modified matrices were fabricated by the hot-press process via the curing press machine (QLB $40 \mathrm{~T}$ ) under $5 \mathrm{MPa}$. Temperature and pressure profiles for manufacturing composites are shown in Figure 1. In order to induce the initial cracks between the middle layers, thin release films were partially placed during fabrication. Finally, the composites were cured at $130^{\circ} \mathrm{C}$ for $10 \mathrm{~h}$. The resulting

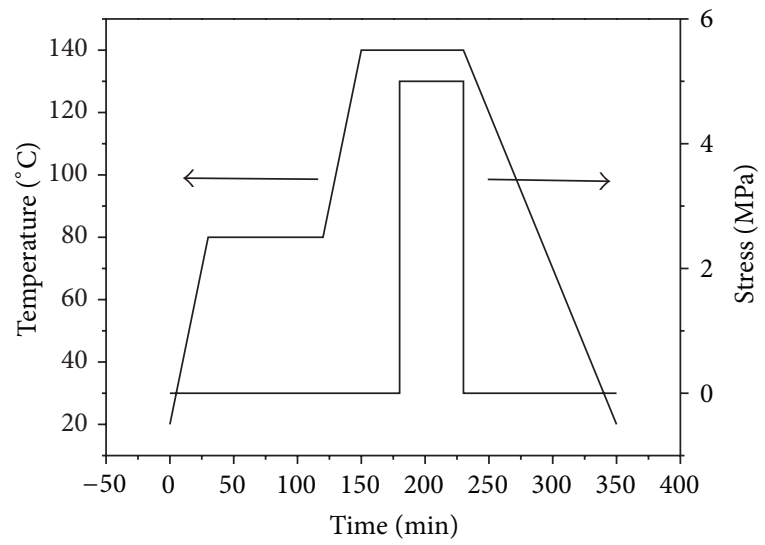

FIGURE 1: Temperature and pressure profiles for manufacturing glass fiber reinforced composites.

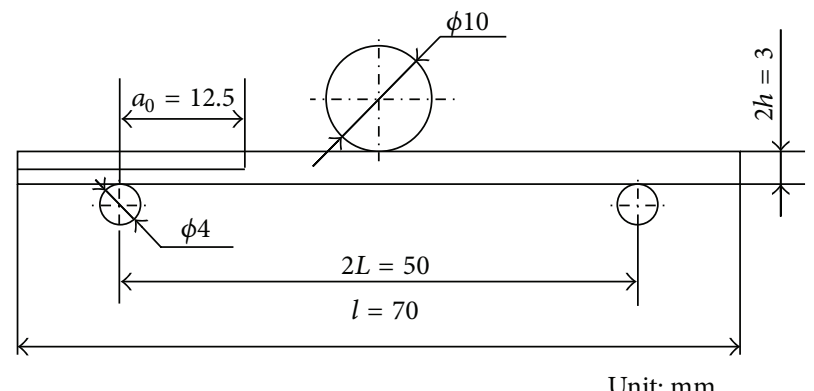

Figure 2: The dimensions of the samples for measurement of $G_{\text {IIc }}$.

glass fiber reinforced composites have a fiber volume content of about $56 \%$ [10]. The specimens for the mechanical tests were cut from the composite plates. The dimensions of the samples for measurement of $G_{\text {IIC }}$ are shown Figure 2.

2.3. Measurement. In the end notched flexure (ENF) test, the critical energy release rate is determined by [11]:

$$
\begin{gathered}
G_{\mathrm{IIc}}=\frac{9 P_{1}^{2} a_{1}^{2} C_{1}}{2 b\left(3 a_{1}^{3}+2 L^{3}\right)}, \\
a_{1}=\left[\frac{C_{1}}{C_{0}} a_{0}^{3}+\frac{2}{3}\left(\frac{C_{1}}{C_{0}}-1\right) L^{3}\right]^{1 / 3},
\end{gathered}
$$

where $a_{0}$ and $a_{1}$ are the initial crack length and the crack length at the critical load, respectively. $C_{0}$ indicates the compliance within initial elastic deformation without crack growth and $C_{1}$ indicates the compliance at the critical load. $P_{1}$ is the critical load which can be determined by the maximum load or $5 \%$ offset load according to the load-displacement curve. $b$ and $2 L$ represent the width and the span length of the specimen, respectively. All the tests were performed using an Instron 5882 universal machine with $5 \mathrm{kN}$ load cell. The crosshead rate was $2 \mathrm{~mm} / \mathrm{min}$ at both RT and $77 \mathrm{~K}$. The cryogenic temperature condition was achieved by immersing the specimens completely in a liquid nitrogen filled cryostat to ensure the uniform temperature of $77 \mathrm{~K}$ [12]. At least five specimens were tested for each composition. 
TABLE 1: Interlaminar fracture toughness at RT and $77 \mathrm{~K}$ for the composites based on unmodified and modified epoxy resins.

\begin{tabular}{|c|c|c|c|c|c|c|}
\hline \multirow{2}{*}{ Matrix } & \multirow{2}{*}{ DGEBF (g) } & \multirow{2}{*}{ DETD (g) } & \multirow{2}{*}{ MWCNT (g) } & \multirow{2}{*}{ BGE (g) } & \multicolumn{2}{|c|}{$G_{\text {IIc }}\left(\mathrm{kJ} / \mathrm{m}^{2}\right)$} \\
\hline & & & & & RT & $77 \mathrm{~K}$ \\
\hline A & 100 & 25.8 & & & $1.40 \pm 0.03$ & $3.25 \pm 0.25$ \\
\hline B & 99.5 & 25.7 & 0.5 & & $1.46 \pm 0.08$ & $3.63 \pm 0.40$ \\
\hline $\mathrm{C}$ & 100 & 28.4 & & 10 & $1.59 \pm 0.04$ & $3.99 \pm 0.42$ \\
\hline $\mathrm{D}$ & 99.5 & 28.3 & 0.5 & 10 & $1.72 \pm 0.07$ & $4.27 \pm 0.32$ \\
\hline
\end{tabular}

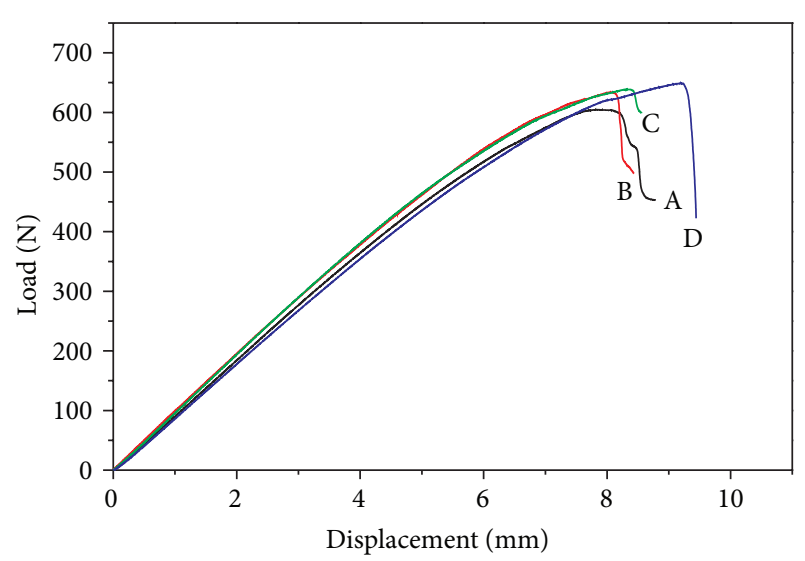

Figure 3: Typical ENF load-displacement curves at room temperature for (A) unmodified epoxy/glass fiber composite, (B) MWCNT modified epoxy/glass fiber composite, (C) BGE modified epoxy/glass fiber composite, and (D) both MWCNT and BGE modified epoxy/glass fiber composite.

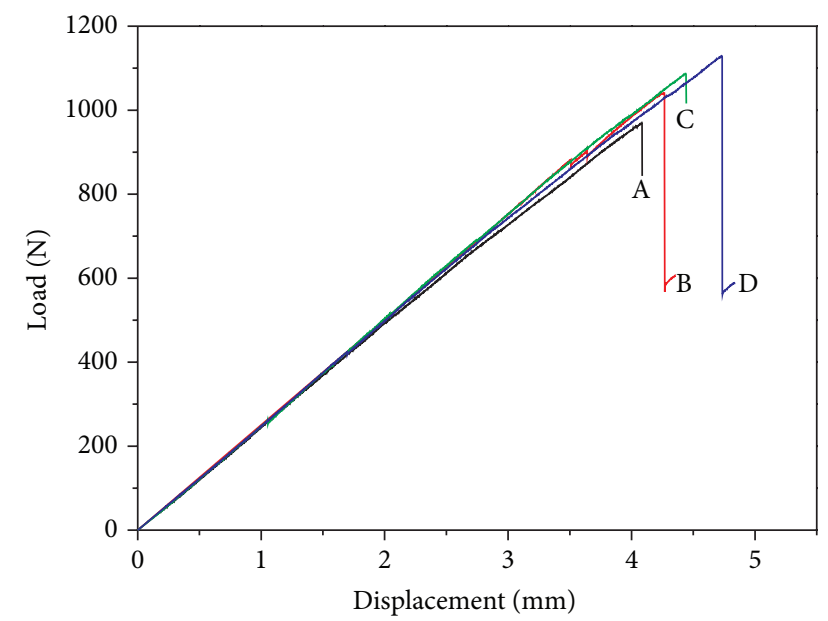

FIgURE 4: Typical ENF load-displacement curves at $77 \mathrm{~K}$ for (A) unmodified epoxy/glass fiber composite, (B) MWCNT modified epoxy/glass fiber composite, (C) BGE modified epoxy/glass fiber composite, and (D) both MWCNT and BGE modified epoxy/glass fiber composite.

The fracture surfaces of the composites were evaluated by scanning electron microscopy (SEM, Hitachi S-4300) at an accelerating voltage of $10 \mathrm{kV}$. All specimens were coated with a thin layer of gold to eliminate charging effects.

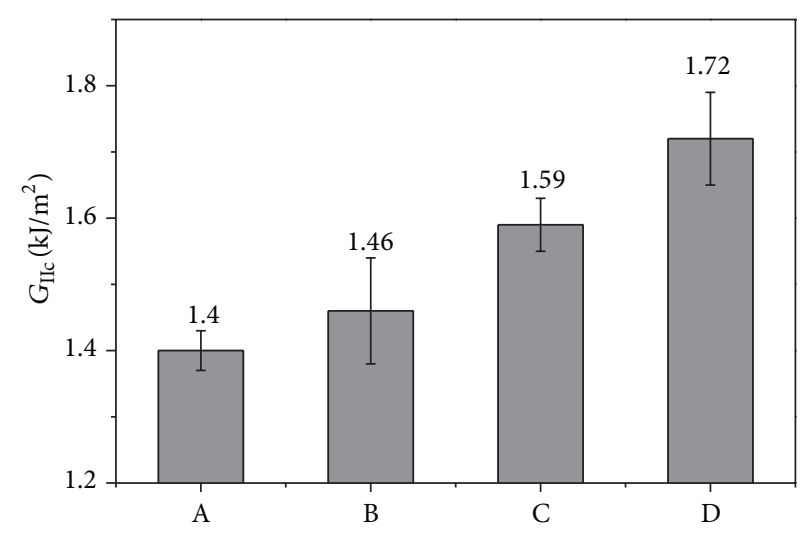

FIgURE 5: The interlaminar fracture toughness at room temperature for (A) unmodified epoxy/glass fiber composite, (B) MWCNT modified epoxy/glass fiber composite, (C) BGE modified epoxy/glass fiber composite, and (D) both MWCNT and BGE modified epoxy/glass fiber composite.

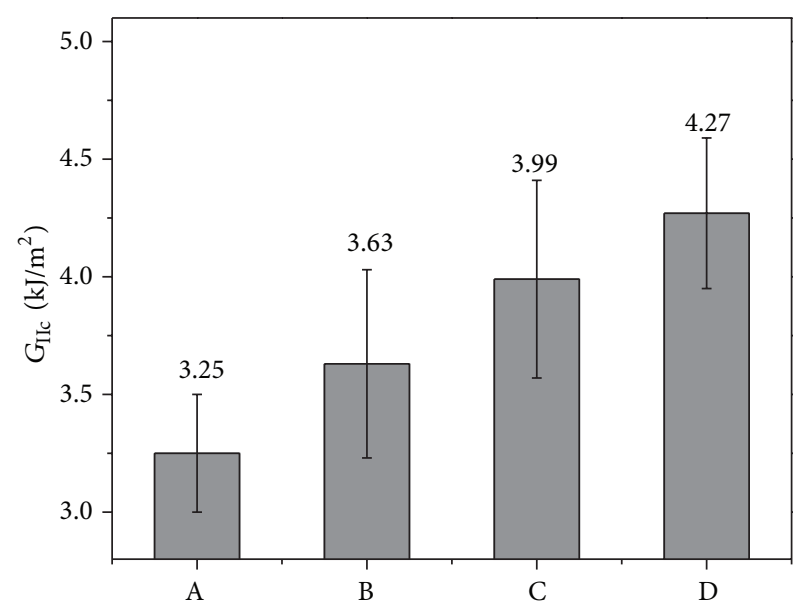

FIGURE 6: The interlaminar fracture toughness at $77 \mathrm{~K}$ for (A) unmodified epoxy/glass fiber composite, (B) MWCNT modified epoxy/glass fiber composite, (C) BGE modified epoxy/glass fiber composite, and (D) both MWCNT and BGE modified epoxy/glass fiber composite.

\section{Results and Discussion}

3.1. Mode II Interlaminate Fracture Toughness. Typical ENF load-displacement curves at room temperature (RT) and liquid nitrogen temperature $(77 \mathrm{~K})$ for the composites are shown in Figures 3 and 4, respectively. At RT, the applied load 

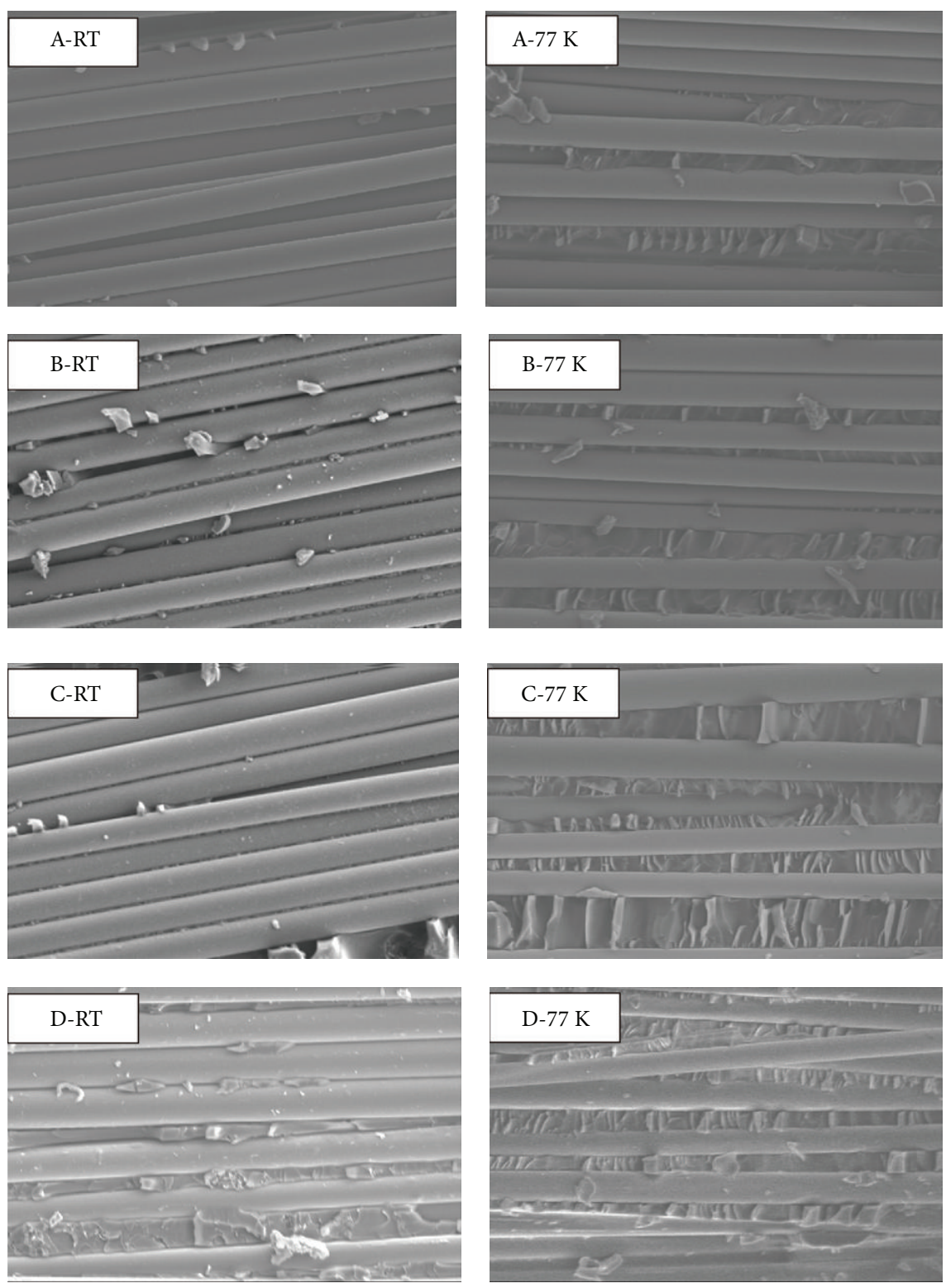

$50 \mu \mathrm{m}$

FIGURE 7: SEM images for the fracture surfaces (crack growth from left to right) after testing at RT and $77 \mathrm{~K}$ of (A) unmodified epoxy/glass fiber composite, (B) MWCNT modified epoxy/glass fiber composites, (C) BGE modified epoxy/glass fiber composite, and (D) both MWCNT and BGE modified epoxy/glass fiber composites.

shows nonlinearity at a relatively low load about 300 N. After attaining the maximum value, the load decreases gradually to the failure. In contrast, at $77 \mathrm{~K}$, the applied load shows a linear relationship with the displacement and unstable crack growth occurs when the maximum value is reached. Moreover, the maximum load at $77 \mathrm{~K}$ is much higher than that at RT. In addition, it should be noted that the maximum load for the composite based on the modified epoxy matrix is higher than that based on the pure epoxy matrix at both RT and $77 \mathrm{~K}$.

The results for the interlaminate fracture toughness at RT and $77 \mathrm{~K}$ are shown in Figures 5 and 6 , respectively. It can be easily noticed that $G_{\text {IIc }}$ of the composites based on the modified matrix is higher than that of the composite based on the unmodified epoxy matrix at both RT and $77 \mathrm{~K}$. Moreover, $G_{\text {IIc }}$ at $77 \mathrm{~K}$ is much higher than that at RT for the same composite. When the temperature decreased from RT to $77 \mathrm{~K}$, the chemical bond of the epoxy matrix would shrink and the binding forces between matrix and fiber could become stronger [8]. The higher mechanical performance at $77 \mathrm{~K}$ compared to RT might be attributed to the stronger binding forces at $77 \mathrm{~K}$ compared to RT.

The data for the interlaminar fracture toughness at RT and $77 \mathrm{~K}$ for the composites based on unmodified and modified epoxy matrices are given in Table 1. At RT, $G_{\text {IIc }}$ of Samples B and C are $4.3 \%$ and $13.6 \%$ higher compared to Sample A, respectively. In particular, the incorporation 
of both MWCNTs and BGE (Sample D) results in 22.9\% improvement in $G_{\text {IIc }}$ compared to Sample A. On the other hand, at $77 \mathrm{~K}, G_{\text {IIc }}$ of Samples B and C are improved by $11.7 \%$ and $22.8 \%$ compared to Sample A, respectively. Moreover, the $G_{\text {IIc }}$ value of Sample D is enhanced by $31.4 \%$ compared to Sample A. Consequently, it can be seen that the simultaneous incorporation of MWCNTs and BGE into the epoxy resin leads to the maximum enhancements in $G_{\mathrm{IIc}}$. In addition, the enhancement in $G_{\text {IIc }}$ at $77 \mathrm{~K}$ was higher than that at RT, this was likely because the chemical bond and molecules of the epoxy matrix would shrink and the binding forces between molecules would become stronger when the temperature decreased from RT to $77 \mathrm{~K}[8]$.

3.2. Microstructure of the Composites. The SEM images are presented in Figure 7 for the fracture surfaces of the ENF specimens. It is revealed that at RT, GF of the composite samples with modified matrices have a rougher surface than those of Sample A. The fracture surface observation coincides with the results for $G_{\text {IIc }}$ of samples. This indicates that the incorporation of MWCNTs and BGE into the conventional GFRP composites based on the pure epoxy matrix creates an increased fracture surface due to crack deflection [13], which will lead to the enhancement in the interlaminar fracture toughness. Sample D with the simultaneous introduction of MWCNTs and BGE into the epoxy resin shows the noticeable effect on the improvement of interlaminar fracture toughness.

At $77 \mathrm{~K}$, the decrease in temperature makes the epoxy more brittle and reduces its strain to failure. The hackle mark features are shown in Figure 7. These hackle patterns are likely caused by secondary cracks [14]. The hackle patterns are more obvious at $77 \mathrm{~K}$ than at RT. The increased fracture surface of the hackle pattern morphology means more surface energy dissipation and therefore an increase of the interlaminar fracture toughness compared to the RT case. The hackle pattern formation also helps to reduce the stress (or strain) concentration at the tip of the principal crack [15]. Therefore, it is reasonable to observe that the simultaneous introduction of MWCNTs and BGE into the epoxy matrix has brought about the significant enhancement in mode II interlaminar fracture toughness.

\section{Conclusions}

In this work, glass fiber reinforced composites have been prepared by the hand lay-up hot press process based on unmodified and modified epoxy matrices by introducing MWCNTs and BGE into a pure epoxy resin in modifying the epoxy resins. Mode II interlaminar fracture toughness $\left(G_{\text {IIc }}\right)$ of the glass fiber reinforced composites has been investigated at both room temperature (RT) and cryogenic temperature $(77 \mathrm{~K})$ to examine the effect of the matrix modification. It has been clearly demonstrated that the epoxy modification by both MWCNTs and BGE can lead to great enhancements in $G_{\text {IIC }}$ at both RT and $77 \mathrm{~K}$.

\section{Conflict of Interests}

The authors declare that there is no conflict of interests regarding the publication of this paper.

\section{Acknowledgments}

This work was financially supported by the National Natural Science Foundation of China (nos. 51373187 and 11372312) and the Beijing Municipal Natural Science Foundation (no. 2122055).

\section{References}

[1] Z. K. Chen, G. Yang, J. P. Yang, S. Y. Fu, L. Ye, and Y. G. Huang, "Simultaneously increasing cryogenic strength, ductility and impact resistance of epoxy resins modified by n-butyl glycidyl ether," Polymer, vol. 50, no. 5, pp. 1316-1323, 2009.

[2] S. Wang, Z. Liang, T. Liu, B. Wang, and C. Zhang, "Effective amino-functionalization of carbon nanotubes for reinforcing epoxy polymer composites," Nanotechnology, vol. 17, no. 6, pp. 1551-1557, 2006.

[3] P. Guo, X. Chen, X. Gao, H. Song, and H. Shen, "Fabrication and mechanical properties of well-dispersed multiwalled carbon nanotubes/epoxy composites," Composites Science and Technology, vol. 67, no. 15-16, pp. 3331-3337, 2007.

[4] L. Guadagno, L. Vertuccio, A. Sorrentino et al., "Mechanical and barrier properties of epoxy resin filled with multi-walled carbon nanotubes," Carbon, vol. 47, no. 10, pp. 2419-2430, 2009.

[5] Q. F. Cheng, J. P. Wang, J. J. Wen et al., "Carbon nanotube/epoxy composites fabricated by resin transfer molding," Carbon, vol. 48, no. 1, pp. 260-266, 2010.

[6] Y. Breton, G. Désarmot, J. P. Salvetat et al., "Mechanical properties of multiwall carbon nanotubes/epoxy composites: influence of network morphology," Carbon, vol. 42, no. 5-6, pp. 1027-1030, 2004.

[7] Y. Shindo, F. Narita, and T. Sato, "Analysis of mode II interlaminar fracture and damage behavior in end notched flexure testing of GFRP woven laminates at cryogenic temperatures," Acta Mechanica, vol. 187, pp. 231-240, 2006.

[8] Z.-K. Chen, J.-P. Yang, Q.-Q. Ni, S.-Y. Fu, and Y.-G. Huang, "Reinforcement of epoxy resins with multi-walled carbon nanotubes for enhancing cryogenic mechanical properties," Polymer, vol. 50, no. 19, pp. 4753-4759, 2009.

[9] Y. Liu, H. M. Xiao, Q. P. Feng, and S. Y. Fu, "Synergistic effect of carbon nanotubes and n-butyl glycidyl ether on matrix modification for improvement of tensile performance of glass fiber/epoxy composites," Composites A, vol. 62, pp. 39-44, 2014.

[10] Y. Liu, J.-P. Yang, H.-M. Xiao et al., "Role of matrix modification on interlaminar shear strength of glass fibre/epoxy composites," Composites B: Engineering, vol. 43, no. 1, pp. 95-98, 2012.

[11] W.-X. Wang, M. Nakata, Y. Takao, and T. Matsubara, "Experimental investigation on test methods for mode II interlaminar fracture testing of carbon fiber reinforced composites," Composites A: Applied Science and Manufacturing, vol. 40, no. 9, pp. 1447-1455, 2009.

[12] J. P. Yang, G. Yang, G. Xu, and S. Y. Fu, "Cryogenic mechanical behaviors of MMT/epoxy nanocomposites," Composites Science and Technology, vol. 67, no. 14, pp. 2934-2940, 2007.

[13] T. Yokozeki, Y. Iwahori, M. Ishibashi et al., "Fracture toughness improvement of CFRP laminates by dispersion of cup-stacked 
carbon nanotubes," Composites Science and Technology, vol. 69, no. 14, pp. 2268-2273, 2009.

[14] H. Lau and R. E. Rowlands, "Fracture morphology of composites tested at RT and 77K," Advances in Cryogenic Engineering, vol. 36, pp. 913-919, 1990.

[15] Y. Shindo, D. Shinohe, S. Kumagai, and K. Horiguchi, "Analysis and testing of mixed-mode interlaminar fracture behavior of glass-cloth/epoxy laminates at cryogenic temperatures," Journal of Engineering Materials and Technology, Transactions of the ASME, vol. 127, no. 4, pp. 468-475, 2005. 

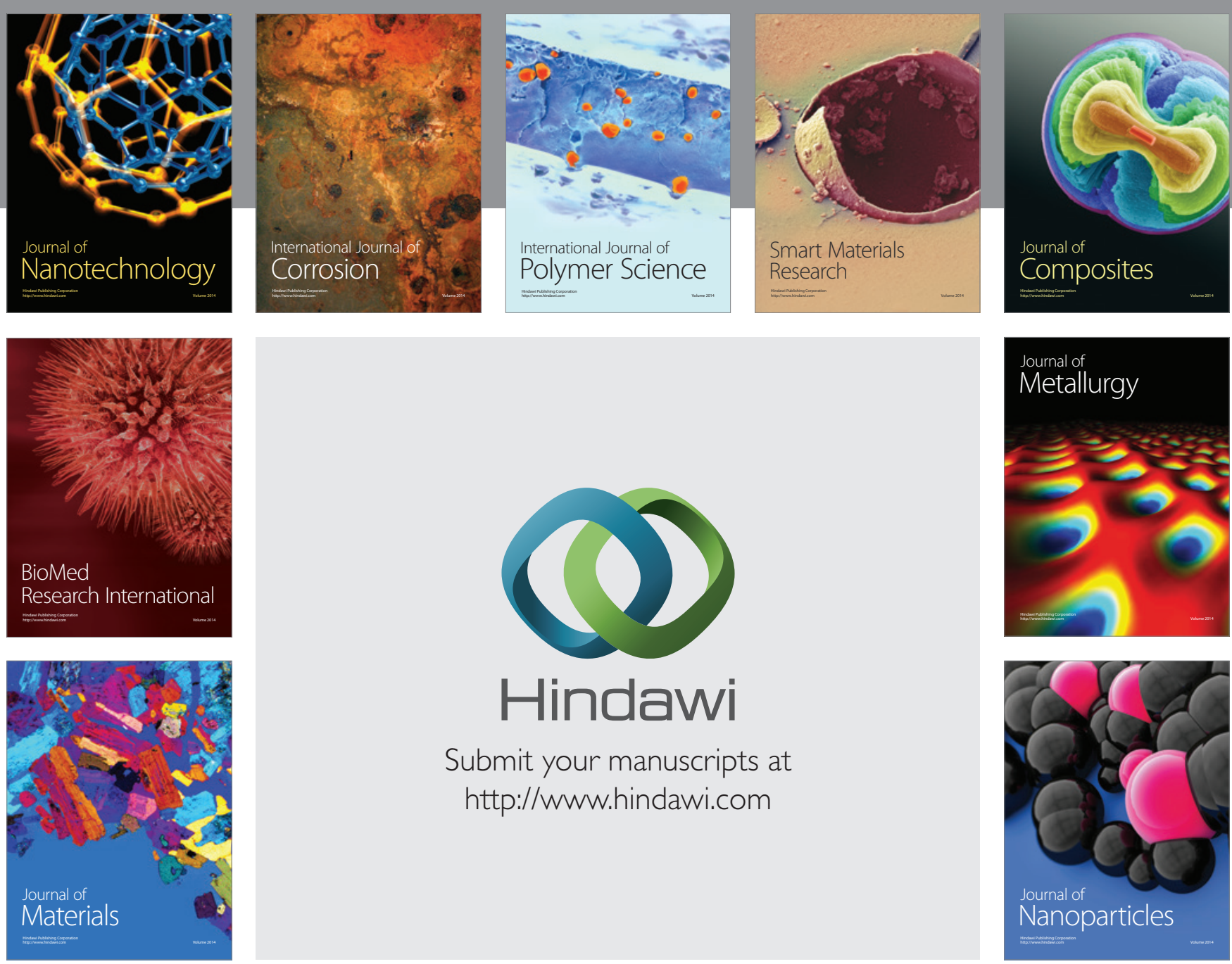

Submit your manuscripts at http://www.hindawi.com
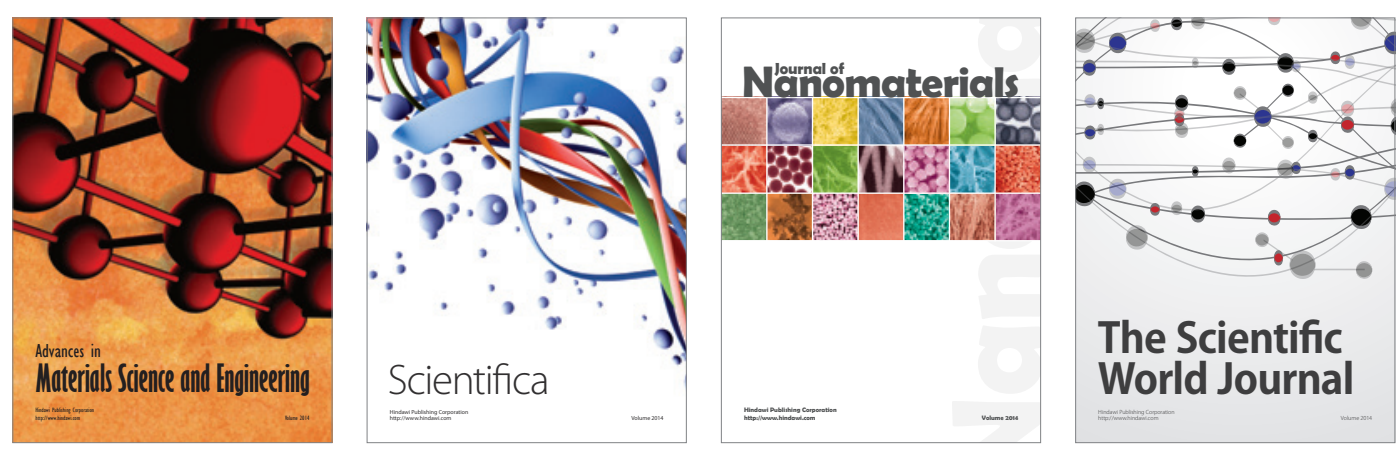

\section{The Scientific World Journal}
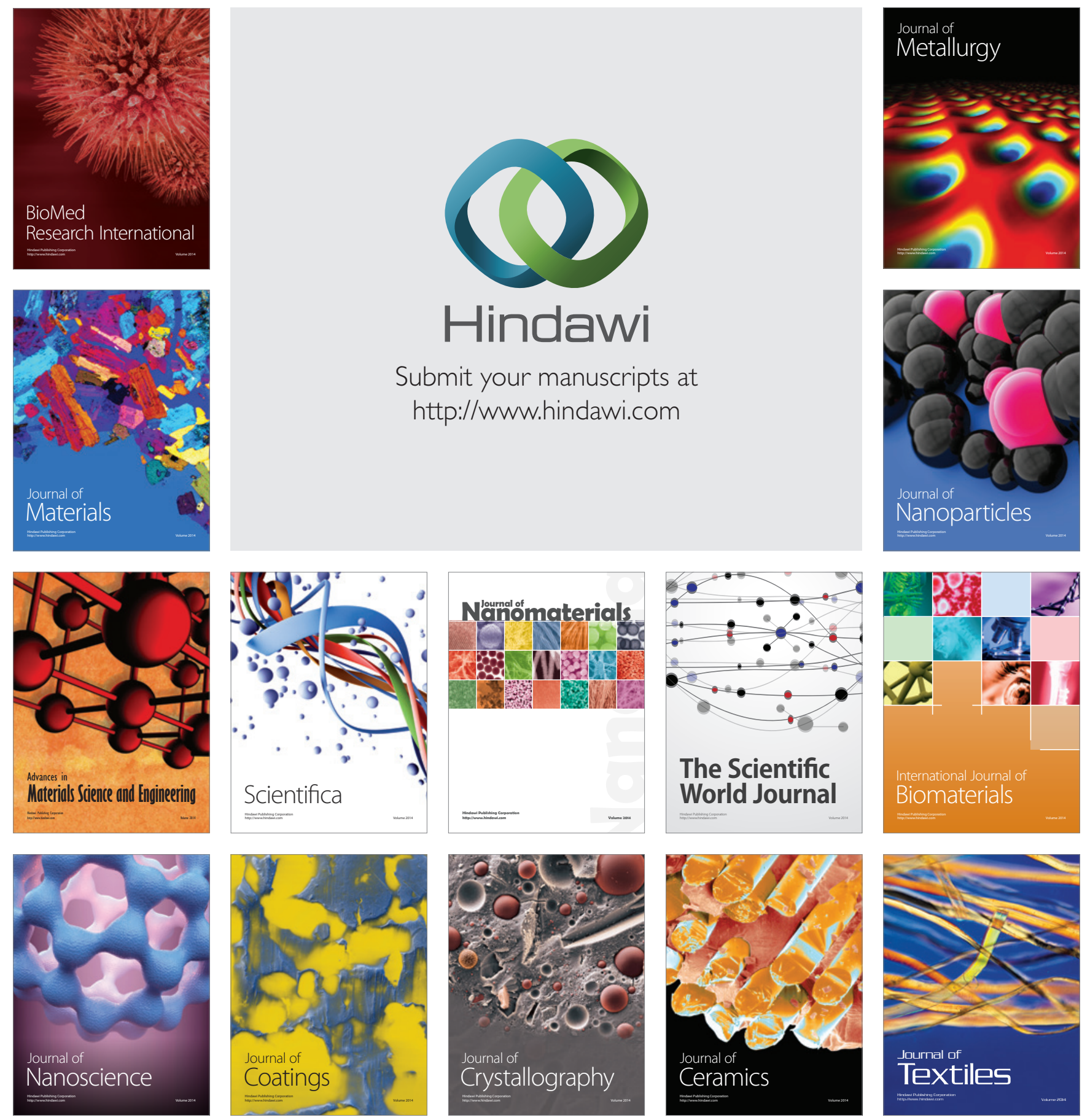